\title{
Bending tests on GLT beams having well-known local material properties
}

\author{
Gerhard Fink • Andrea Frangi · Jochen Kohler
}

Received: 19 February 2014/ Accepted: 12 September 2014/Published online: 28 October 2014

(C) RILEM 2014

\begin{abstract}
In the present paper a summary of experimental investigations on GLT beams, having wellknown local material properties, is presented. The main objective of the presented project, was the investigations of the influence of varying material properties on the load-bearing behaviour of GLT beams. From altogether 24 GLT beams the loadbearing capacity, the bending stiffness, the type of failure and the deformation behaviour of knot clusters and finger joint connections located in highly stressed areas of the GLT beams are investigated. The test result can be used to validate numerical models for the prediction of the load-bearing capacity of GLT beams. The principle of such a validation is illustrated for a numerical model developed by the authors.
\end{abstract}

Keywords GLT · Optical strain measurement · Varying material properties $\cdot$ Finger joint connections

The article is a summary of the test report Bending Tests on Glued Laminated Timber Beams with Well-Known Material Properties [21].

G. Fink $(\bowtie)$ - A. Frangi

Institute of Structural Engineering, ETH Zurich, Stefano-

Franscini-Platz 5, 8093 Zurich, Switzerland

e-mail: fink@ibk.baug.ethhz.ch

J. Kohler

Department of Structural Engineering, NTNU Trondheim, Rich. Birkelandsvei 1A, 7491 Trondheim, Norway

\section{Introduction}

Glued laminated timber (GLT) is one of the most relevant products in timber engineering. The loadbearing behaviour of GLT beams is substantially influenced by the material properties of the used timber boards and the quality of finger joint connections (FJ). As a natural grown material, timber demonstrates a large variability of its material properties. The variability can be observed between timber boards and within timber boards. The between-member variability, or more precisely the variability of the undisturbed timber (referred to as clear wood), is related to different growth and sawing characteristics (e.g. growth region, sapwood-heart-wood), whereas the within-member variability is highly dependent on morphological characteristics of the tree, especially it is dependent on knots and their arrangement (see e.g. [19], for an overview about investigations and models that are describing the between and within-member variability).

In GLT beams the variability of the material properties is slightly reduced due to homogenisation. However, compared to other building materials it is still relatively large. The most critical sections of GLT beams are large knot clusters and FJ located in highly stressed areas of the GLT beams. The failure usually occur there.

\subsection{Experimental investigations on GLT beams}

In respect to the importance of GLT, in the area of timber engineering, its load-bearing behaviour has 
been investigated in numerous of experimental investigations. Well-known examples are the investigations by $[1,3-8,15,16,22-26,35,36]$.

In most of the above mentioned studies no or only marginal effort was taken on the investigation of the influence of the beam setup; i.e. the exact material properties of the timber boards, such as the position and dimension of knots, within the GLT beams are usually not documented-often only the strength class of the source material is known.

Exceptions are the investigations of [16] and [36], where reference tests on timber boards and FJ are performed. As a result, the material properties of the timber boards and the FJ that are built in the GLT beams could be estimated more precisely.

More detailed was the investigation performed by [24], where 20 GLT beams were tested. From all timber boards that are built in the tensile loaded area of the GLT beams, the density $(\rho)$, the dynamic modules of elasticity based on eigenfrequency $\left(E_{\mathrm{dyn}, \mathrm{F}}\right)$, and the two largest knot clusters were measured before the GLT fabrication. However, the position of the timber boards within the GLT beams are not explicitly documented. In addition, Frese et al. [24] performed reference test on timber boards and FJ.

So far, the most detailed investigation was performed by $[4,5]$. The GLT beams are tested, where the material properties (dimension and position of knots, density and eigenfrequency of the timber boards) of the lowest two lamellas are known. In addition Ehlbeck and Colling [4] performed 21 reference tests to identify the tensile capacity of FJ. During the GLT fabrication attention was paid that no FJ is located in the highly stressed area of the two lowest lamellas, to avoid that the test results are affected by FJ. Only in nine GLT beams, a FJ was placed in the highly stressed area - the majority of these beams failed within the FJ.

\subsection{Influence of finger joint connections}

In addition to knot clusters also FJ can be considered as local weak sections within GLT beams. In general the load-bearing capacity of FJ is significantly smaller than that of the adjacent clear wood, whereas the stiffness is comparable [7, 29]. Trough the relatively large stiffness, compared to their tensile strength, FJ are attraction high stresses.
The influence of FJ was investigated in numerous studies. Consistence is that a certain amount of the tested GLT beam failed in areas of FJ. However, the amount of the failures where FJ are involved is varying between the investigations. [3] analysed the influence of FJ on a compilation of numerous studies; altogether the compilation consist 1,767 GLT beams. The experimental investigations from this literature survey were performed between 1924 and 1988 on GLT beams fabricated out of timber boards of different specimens. Only in 277 GLT beams a FJ was located in the lowest lamella within the area of the maximal bending moment. The investigation show that about $79 \%$ of those GLT beam failed through the FJ. In addition [3] tested 42 GLT beams himself. The results show that the influence of FJ on the type of failure is directly related to the amount of knots within the timber boards. GLT beams produced out of timber boards having large knot clusters failed through the knot cluster, whereas GLT beams fabricated out of timber boards with no or only small knot clusters failed in the area of FJ, by the majority. In the study of $[32]^{1}$ only $31 \%$ failed through FJ. [1] presented the failure within the lowest lamella of altogether 50 GLT beams, of the strength classes GL32c and GL36c. 6 FJfailure, 37 timber failure (knot cluster or clear wood) and 7 combined failure (FJ and timber) are documented. Thus only 13 of the GLT beams failed connected to a FJ (26\%). Conspicuous is that within the lower strength grade significantly more FJ-failures (9) occur than in the upper strength class (4). [36] investigated 115 GLT beams. The investigation show that the amount of failures connected with $\mathrm{FJ}$ is increasing with increasing timber quality. GLT fabricated out of timber boards ${ }^{2}$ MS10 failed in 5-9 \% trough FJ, MS13 in $11 \%$, and MS17 in 24-39\%. Further it seems that the probability of a FJ-failure is decreasing with increasing GLT dimensions. [16] have investigated altogether 312 GLT beam produced out of Norwegian spruce of three different strength classes. Under consideration of the required values of the source material the strength classes are comparable to GL28h, GL32c, and GL32h according to EN 1194

\footnotetext{
1 quoted in [38]

2 the timber boards were graded according to ÖNORM DIN 4074 [33], and fulfil the requirements of strength class C24, C35 and $\mathrm{C} 40$ according to EN 338 [12]
} 
([9]). In 23, 34 and $44 \%$ of the GLT beams a FJfailure is detected, respectively.

In conclusion, based on the literature survey, it can be stated that knot clusters and FJ are the most critical areas in GLT beams. Due to the lower amount of knots in higher strength grades, the influence of FJ is increasing. An other outcome of the literature survey, is that the quality of FJ seems to be increased within the last decades; i.e. the amount of FJ-failure is significantly smaller within more recent studies, even for high strength classes. This might be the result of the quality increase of the GLT producers.

In order to get a better understanding about the influence of varying material properties on the loadbearing capacity of GLT beams, a research project was initiated at ETH Zurich. 24 GLT beams having wellknown local material properties are fabricated and investigated. Thereby, it is particular focused on the influence of knot clusters and FJ, on the load-bearing behaviour of the GLT beams.

\section{Materials and methods}

The GLT beams are fabricated out of $2 \times 200$ timber boards of two strength grades L25 and L40 (Norway spruce) - the grading of the timber boards is performed according to EN 14081-4 [11] by the GoldenEye-706 grading device [27]. This is a grading device that combines the measurement of the dynamic modulus of elasticity based on eigenfrequency with a $\mathrm{X}$-ray measurement. The latter one, the X-ray measurement, is used for detecting knots. Due to the significant larger density of knots, compared to the density of defect-free timber, knots are getting visible in a grey scale image. They can be detected in size and position, by using image processing. As a result, from all 400 timber boards, machine-grading indicators, i.e. an estimation of the dynamic modulus of elasticity $\left(E_{\mathrm{m}}\right)$ and a knot indicator $\left(K_{\mathrm{m}}\right)$, are known. Here, machine-grading indicators denote indicators that are measured during the grading process. Before the GLT fabrication, the timber boards are investigated nondestructively. Afterwards, out of the investigated timber boards, 24 GLT beams having well-known local material properties are fabricated. They are investigated destructively during four-point-bending tests.

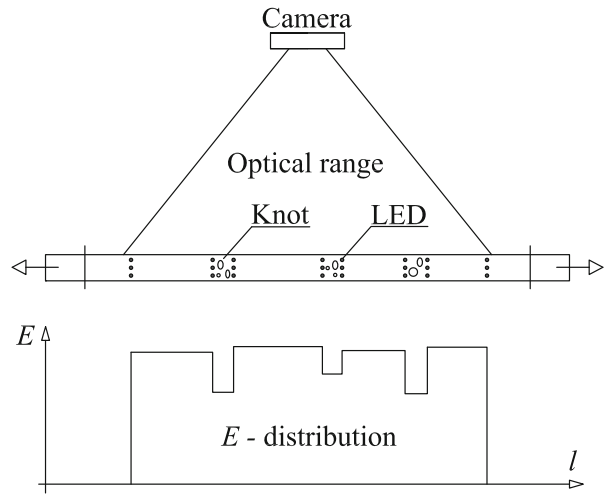

Fig. 1 Illustration of the experimental setup

\subsection{Investigations on timber boards}

At first the timber boards, which are used for the GLT fabrication, are investigated non-destructively. From all timber boards the dimensions and the position of each knot with a diameter larger than $10 \mathrm{~mm}$ is assessed and recorded. Based on the measurements different knot parameters are calculated. In the present paper only one knot parameter, the so-called total knot area ratio (tKAR-value), is mentioned. tKAR-value is defined as the ratio between the projected knot area within a length of $150 \mathrm{~mm}$ and the cross sectional area [30].

In addition to the knot measurement, several indicators to predict the mean stiffness (eigenfrequency, ultrasonic runtime and density) and the moisture content are measured. Based on the eigenfrequency and the ultrasonic runtime the corresponding dynamic modulus of elasticities $\left(E_{\mathrm{dyn}, \mathrm{F}}\right.$ and $\left.E_{\mathrm{dyn}, \mathrm{US}}\right)$ of the timber boards are calculated according to Eqs. (1), (2), $[28,37]$. Where, $f_{0}$ is the eigenfrequency, $v$ is the ultrasonic wave speed, $l$ is the length of the timber board, and $\rho$ is the density. Both, $E_{\mathrm{dyn}, \mathrm{F}}$ and $E_{\mathrm{dyn}, \mathrm{US}}$, have to be considered as average values over the entire length of the timber board. The assessed values are corrected to a reference moisture content according to EN 384 [13].

$E_{\mathrm{dyn}, \mathrm{F}}=\left(2 l f_{0}\right)^{2} \rho$

$E_{\mathrm{dyn}, \mathrm{US}}=\rho v^{2}$

On half of the specimens non-destructive tensile tests are performed to estimate the tensile stiffness of timber board sections. Prior to the experiment every 
timber board is subdivided into sections containing knots and sections without knots (see Fig. 1). From each sections the stiffness properties are measured, by using an infrared camera device Optotrak Certus (sType), Northern Digital Inc. According to the fabricator the point measurements accuracy is up to $0.10 \mathrm{~mm}$. However, investigation in our laboratory show that the relative displacement between two measured points can be predict more precise. Please find a detailed description of the conducted tests in [18].

\subsection{Fabrication of GLT beams}

Out of the investigated timber boards, GLT beams having well-known local material properties are fabricated. Each GLT beam contains eight layers of lamellas. The dimensions of the beams are $b \times h \times$ $l=115 \times 320 \times 6,000 \mathrm{~mm}$; hence the ratio $l / h \approx 19$ (see EN 408 [14]). According to EN 14080 [34], timber boards of those strength grades (L25 and L40) fulfil the requirements to produce GLT beams of the strength class GL24h and GL36h, respectively. At this point it has to be mentioned that the strength grade GL36h is no longer existing within the current version of the EN 14080 [10]. However, the new version was not out when the project started and the former code is still valid.

For the fabrication of the GLT beams, the position of each timber board and each FJ are defined, before the GLT fabrication. Thus, GLT beams are fabricated, where the exact position of each particular timber board is precisely-known. These timber boards, where the local stiffness properties are measured, are built in the lower three lamellas of the GLT beams. In all GLT beams a FJ is located in the maximum bending moment area of the lowest lamella. Furthermore, in the second lowest lamella the majority of the lamellas had a FJ in the maximum bending moment area, otherwise the FJ is located nearby the maximum bending moment area, thus still in an area of a large bending moment.

Altogether 24 GLT beams having well-known local material properties are fabricated and investigated. Half of them are fabricated out of timber boards of the strength grades L25 and L40, respectively. Within both strength grades three different types of GLT beams are produced, each four beams. The first type of GLT beams is produced out of randomly selected timber boards. The second and third types are produced with so-called homogeneous or inhomogeneous lamellas in the tensile loaded area of the GLT beams. Here homogeneous lamellas show relatively low mean stiffness properties combined with comparative small within-member variability (small knot clusters). On the other hand inhomogeneous lamellas are having relatively large variability of the material properties within the member; i.e. large knot clusters. The timber boards are subdivided, based on the measurements of the GoldenEye-706 grading device.

The idea behind this subdivision is that GLT beams having 'homogeneous' lamellas in the tensile loaded area can allow larger deformation (low mean stiffness), without large stress peaks within the area of knot clusters (small variability of the material properties). This might lead to an increase of the stress redistribution from the lowest lamella into the lamella located above and thus to an increase of the load-bearing capacity. In contrast to this, GLT beams having 'inhomogeneous' lamellas in the tensile loaded area, should lead to GLT beams where the load-bearing capacity is highly related to the tensile capacity of the weakest section within the lowest lamella.

The arrangement of the timber boards within the GLT beams are randomly, except the lower three lamellas of the homogeneous and the inhomogeneous beams. There the positions of the timber boards are chosen, so that specified arrangements of weak sections occur. Attempts were made that GLT beams are produced (a) where knot clusters are lying above each other, and (b) where knot clusters are arranged diagonal shifted. Thereby it was particular focused on the main stressed area. However, timber is a natural grown material and thus the arrangement of knots is not completely regular. Consequently the majority of the GLT beams include both; knot clusters that are lying above each other and knot clusters that are arranged diagonally shifted.

\subsection{Beam setup-material properties}

Due to the intensive experimental investigations on timber boards combined with the pre-defined arrangement of the timber boards, GLT beams having wellknown local material properties are fabricated. From all 24 GLT beams the following informations are known: (1) position of each FJ, (2) position and dimension of each knot with a diameter larger than 10 
(a) tKAR-value

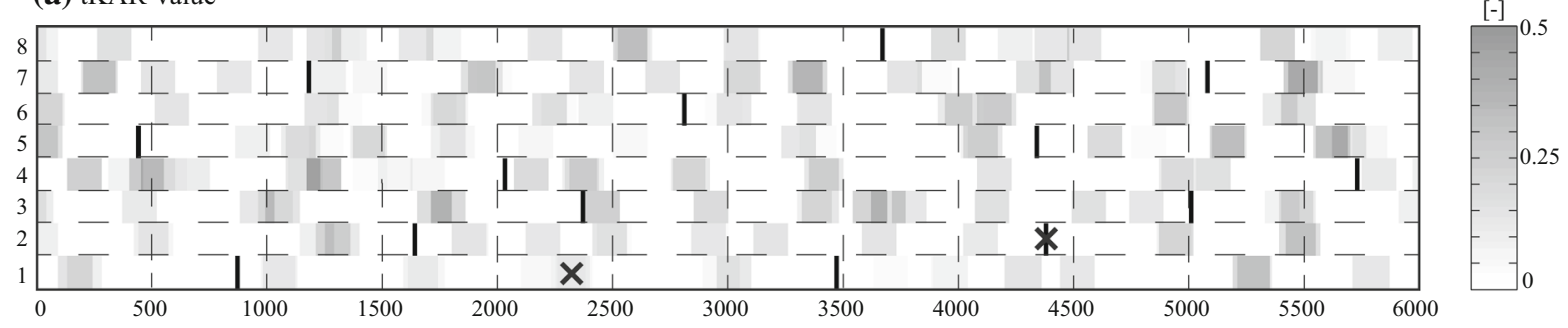

(b) Dynamic modulus of elasticity based on Eigenfrequency measurement

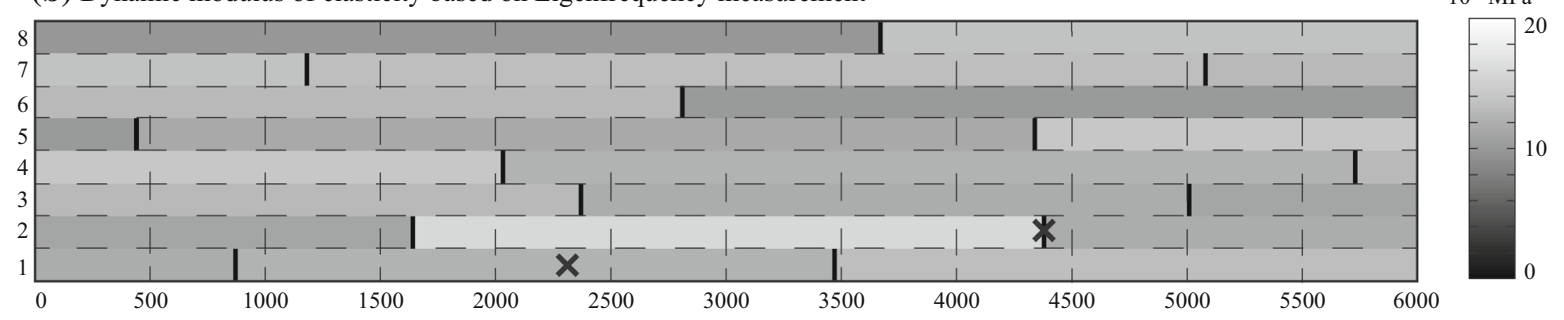

(c) Measured modulus of elasticity
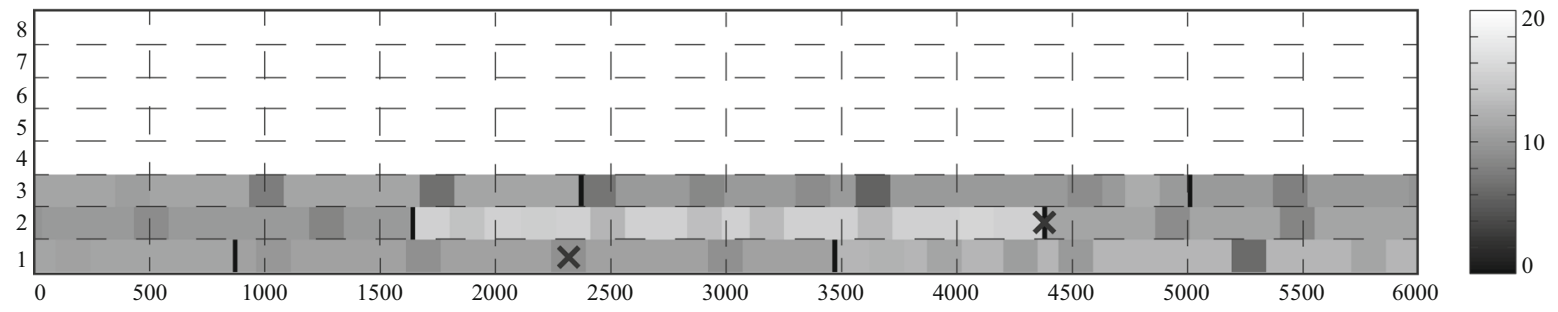

(d) Machine grading indicator - dynamic modulus of elasticity
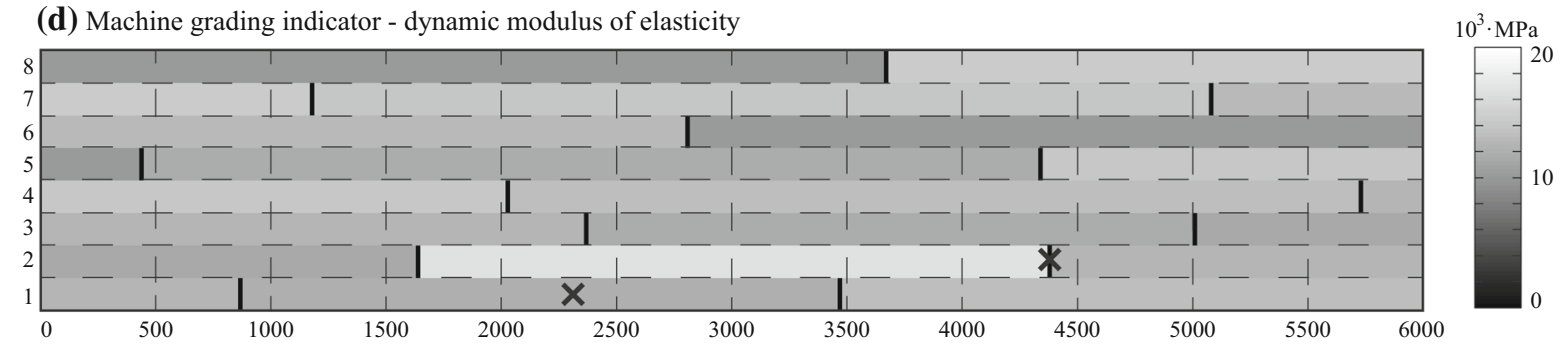

(e) Machine grading indicator - knot parameter

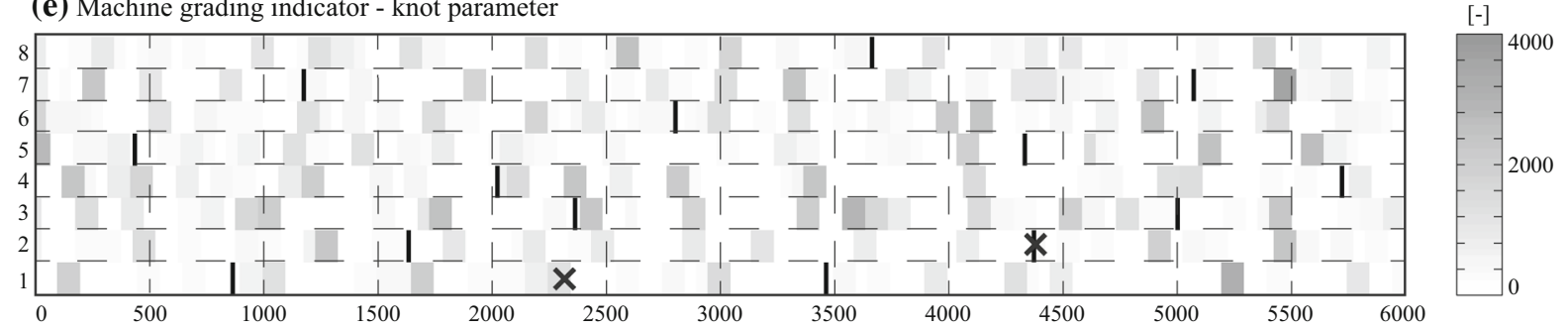

Fig. 2 Material properties of one GLT beam: a tKAR-value, b dynamic modulus of elasticity based on Eigenfrequency measurement $E_{\mathrm{dyn}, \mathrm{F}}$, c measured modulus of elasticityestimated with non-destructive tensile tests, $\mathbf{d}$ machine grading indicator-dynamic modulus of elasticity $E_{\mathrm{m}}$, e machine grading indicator- knot parameter $K_{\mathrm{m}}$; the black lines illustrate FJ, the crosses illustrate the position of failure of the lowest two lamellas 


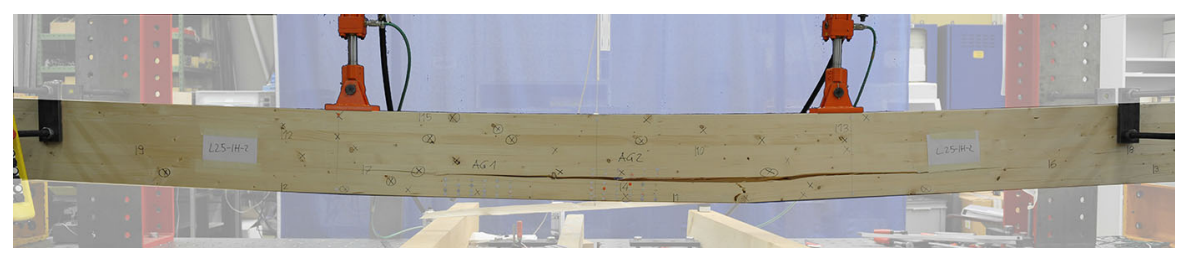

Fig. 3 Failed GLT member (the distance between the points for load transmission is 1,920 mm, the distance between the points for load transmission and the nearer support is $1,880 \mathrm{~mm}$ )

$\mathrm{mm}$, (3) density of each timber board, (4) estimated mean stiffness properties of each timber board $\left(E_{\mathrm{dyn}, \mathrm{F}}\right.$ and $\left.E_{\mathrm{dyn}, \mathrm{US}}\right)$, and (5) measured stiffness properties of each knot cluster and each clear wood section, located in the tensile loaded area of the GLT beams. In addition to the parameters measured in the laboratory, also the machine-grading indicators from the GoldenEye-706 grading device are known: (6) estimation of the dynamic modulus of elasticity $E_{\mathrm{m}}$, and (7) knot parameter $K_{\mathrm{m}}$.

In Fig. 2 the material properties within one GLT beam are illustrated: (a) tKAR-value, (b) dynamic modulus of elasticity based on Eigenfrequency measurement $E_{\mathrm{dyn}, \mathrm{F}}$, (c) measured modulus of elasticity-estimated with non-destructive tensile tests, (d) machine grading indicator-dynamic modulus of elasticity $E_{\mathrm{m}}$, and (e) machine grading indicator-knot parameter $K_{\mathrm{m}}$. The black lines illustrate FJ, the crosses illustrate the position of failure of the lowest two lamellas.

\section{Test results}

The GLT beams are investigated during four-point bending tests (Fig. 3). Thereby, the focus lies on the investigation of global phenomena (load-bearing capacity and bending stiffness), and local phenomena (deformation behaviour of selected areas and type of failure).

From all GLT beams the load-bearing capacity and the bending stiffness are identified and the type of failure is investigated. Additionally, local strains within the GLT beams are analysed using the optical camera device described before. On four GLT beams the strains are analysed over the entire main stressed area (area where the bending moment is maximum). From the other 20 GLT beams the strains are measured on two selected local areas (in general areas containing knot clusters or FJ). To ensure an optimal comparability between the test results all beams are tested with the same moisture content $u=10-12 \%$.

\subsection{Load-bearing capacity \& bending stiffness}

During four-point bending tests each GLT beam is loaded up to failure. The failure is defined as the first explicit crack within the GLT beam that leads to an abruptly, significant deformation of the specimen. The ultimate load $F_{\mathrm{u}}$ is the applied load at the moment of failure. Under consideration of $F_{\mathrm{u}}$ the bending strength $f_{\mathrm{m}, \mathrm{g}}$ is calculated with Eq. (3), according to EN 408 ([14]); here $a$ is the distance between the point of load transmission and the nearer support, $b$ and $h$ are the width and hight of the cross-section.

$f_{\mathrm{m}, \mathrm{g}}=\frac{3 F_{\mathrm{u}} \times a}{b h^{2}}$

The bending strength $f_{\mathrm{m}, \mathrm{g}}$ is estimated on specimens with a cross-section $b \times h=115 \times 320 \mathrm{~mm}$. According to EN 1194 ([9]), $f_{\mathrm{m}, \mathrm{g}}$ should be estimated on specimens with a cross-section of at least $b \times h=150 \times 600 \mathrm{~mm}$. In the case of smaller tested specimens, the estimated bending strength $f_{\mathrm{m}, \mathrm{g}}$ has to be reduced with the size factor $k_{\text {size }}$ according to Eq. (4) to consider the size effect (denoted $f_{\mathrm{m}, \mathrm{g}, \text { size }}$ ).

$$
\begin{aligned}
& f_{\mathrm{m}, \mathrm{g}, \mathrm{size}}=f_{\mathrm{m}, \mathrm{g}} \times k_{\text {size }} \\
& k_{\text {size }}=\left(\frac{b}{150}\right)^{0.05}\left(\frac{h}{600}\right)^{0.1}=0.927
\end{aligned}
$$

The global bending stiffness $E_{\mathrm{m}, \mathrm{g}}$ is estimated based on the measured vertical displacement of the middle point of the GLT beam. The vertical displacement is measured with two different systems; (1) linear variable differential transformer (LVDT) located in the middle of the lower side of the beam, and (2) optical camera device (NDI). With both measurement systems similar displacements are identified. 


\begin{tabular}{|c|c|c|c|c|c|c|c|}
\hline & $\ddot{\widetilde{N}}$ & 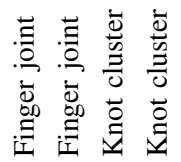 & 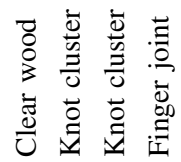 & 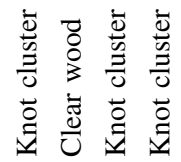 & 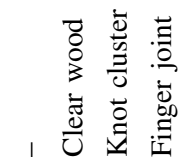 & 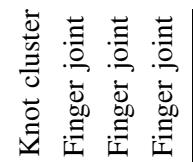 & 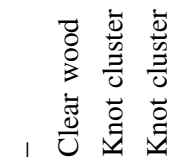 \\
\hline 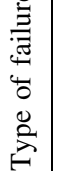 & $\underline{\Delta}$ & 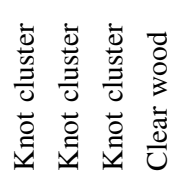 & 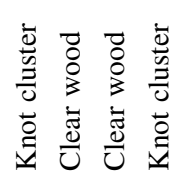 & 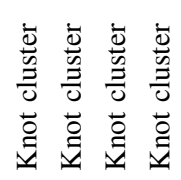 & 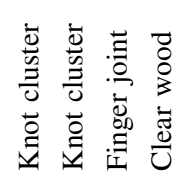 & 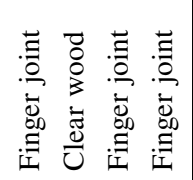 & 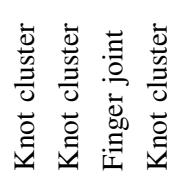 \\
\hline 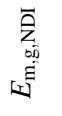 & $\hat{\Xi}^{\overparen{E}}$ & 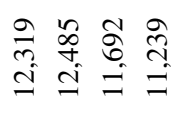 & 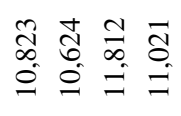 & 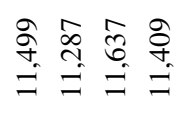 & 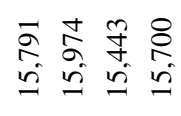 & 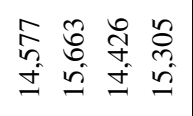 & 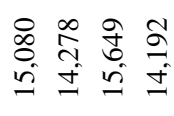 \\
\hline 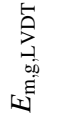 & $\stackrel{\overparen{E}}{\hat{E}^{ \pm}}$ & 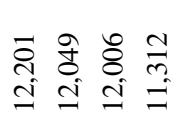 & 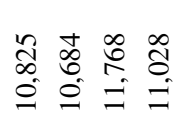 & 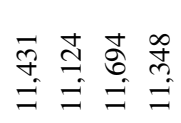 & 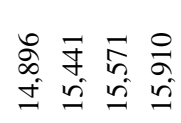 & 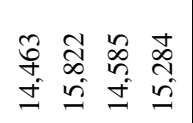 & 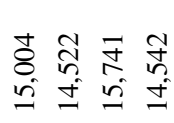 \\
\hline 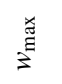 & 亶 & 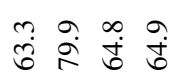 & 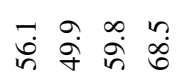 & 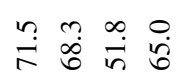 & 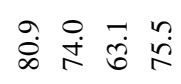 & $\stackrel{0}{\stackrel{i}{i}} \underset{\infty}{\stackrel{0}{d}}$ & 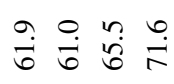 \\
\hline 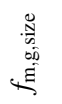 & $\stackrel{\overparen{E}}{\stackrel{E}{\varepsilon}}$ & 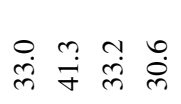 & 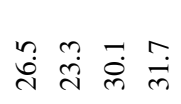 & 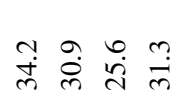 & 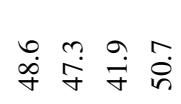 & 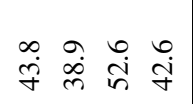 & 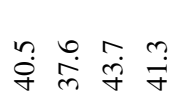 \\
\hline$\stackrel{\infty}{\stackrel{\infty}{E}}$ & $\stackrel{\overparen{E}}{\stackrel{E}{E}^{2}}$ &  & 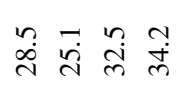 & 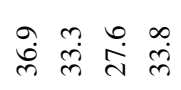 & 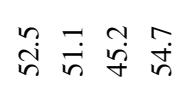 & 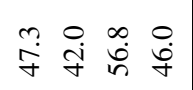 & 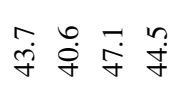 \\
\hline 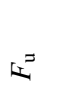 & 妾 & 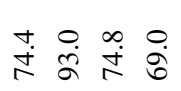 & 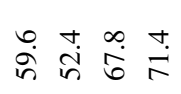 & 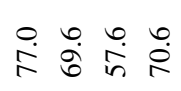 & 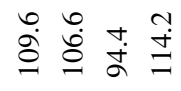 & $\begin{array}{llll}\infty & 0 & 0 & 0 \\
\infty & \infty & \infty & 0 \\
\infty & \infty & 0\end{array}$ & 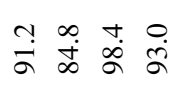 \\
\hline 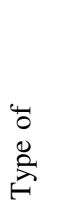 & Еี & 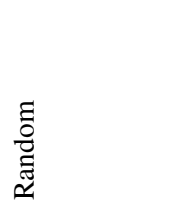 & 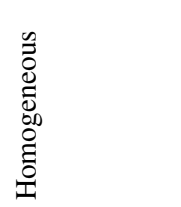 & 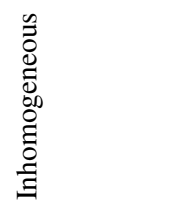 & 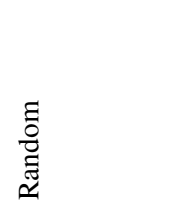 & 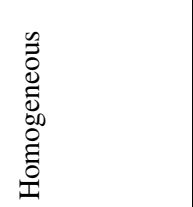 & 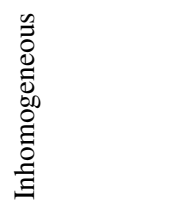 \\
\hline 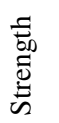 & $\begin{array}{l}\frac{n}{0} \\
\frac{\tilde{g}}{0}\end{array}$ & 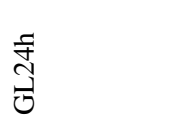 & 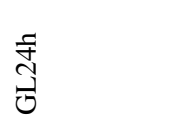 & $\underset{\mathrm{J}}{\stackrel{f}{J}}$ & $\underset{\substack{0 \\
0}}{0}$ & 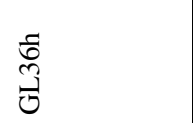 & 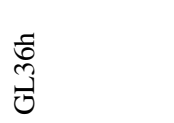 \\
\hline 5 & ह్ & 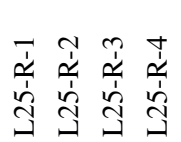 & 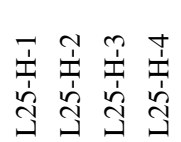 & 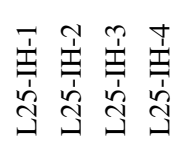 & 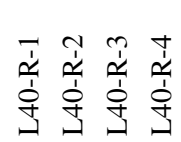 & 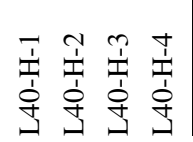 & 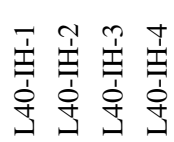 \\
\hline
\end{tabular}


Fig. 4 Test results GL24h: (left) load-bearing capacity, (right) bending stiffness; ${ }^{a}$ required values according to EN 1194 ([9]) and JCSS [31]
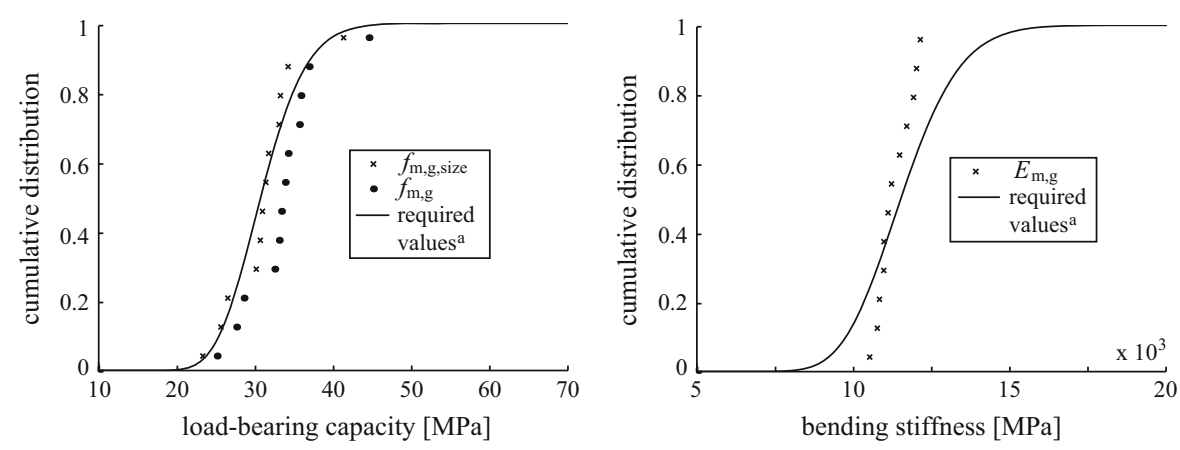

Fig. 5 Test results GL36h: (left) load-bearing capacity, (right) bending stiffness; ${ }^{a}$ required values according to EN 1194 ([9]) and JCSS [31]

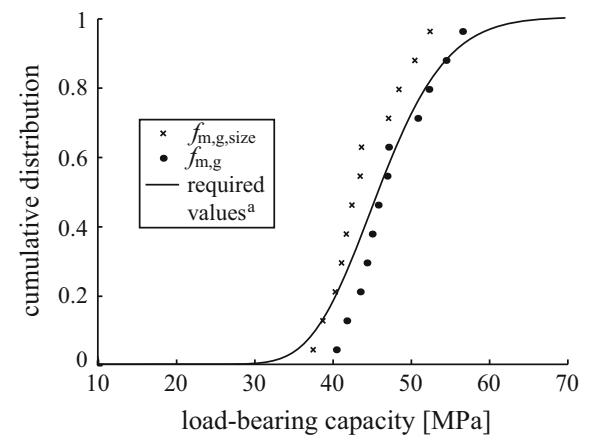

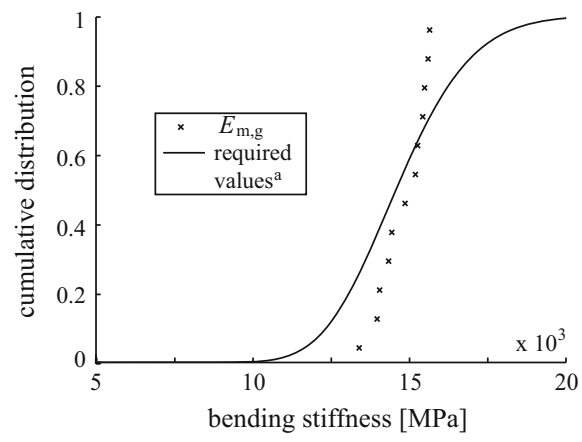

Taking into account the measured force and the associated vertical displacement the global bending stiffness $E_{\mathrm{m}, \mathrm{g}}$ is estimated with Eq. (5) according to EN 408 ([14]), using a linear regression analysis with all data within the interval $0.1-0.4 \quad F_{\mathrm{u}}$. For all specimens the coefficient of correlation $\rho(F, w)>$ 0.99. $F_{2}-F_{1}$ and $w_{2}-w_{1}$ denote the rates of loading and deformation within the load interval $0.1-0.4 F_{\mathrm{u}}$. The shear modulus $G$ was not identified within this research project and assumed infinite in accordance to EN 408 ([14]).

$$
E_{\mathrm{m}, \mathrm{g}}=\frac{3 a l^{2}-4 a^{3}}{2 b h^{3}\left(2 \frac{w_{2}-w_{1}}{F_{2}-F_{1}}-\frac{6 a}{5 G b h}\right)}
$$

The results are summarised in Figs. 4 and 5. Here the black lines corresponds to the required values of the material properties given in EN 1194 ([9]), combined with the recommended COV given in JCSS [31]; $f_{\mathrm{m}, \mathrm{g}, \mathrm{k}}=$ $24 \mathrm{MPa}(\mathrm{COV}=0.15)$ and $E_{\mathrm{m}, \mathrm{g}, \text { mean }}=11,600 \mathrm{MPa}$ $(\mathrm{COV}=0.13)$ for GL24h, and $f_{\mathrm{m}, \mathrm{g}, \mathrm{k}}=36 \mathrm{MPa}$ $(\mathrm{COV}=0.15)$ and $E_{\mathrm{m}, \mathrm{g}, \text { mean }}=14,700 \mathrm{MPa}(\mathrm{COV}=$ 0.13 ) for GL36h. It seems that the strength properties of both strength classes corresponds to the values proposed. The same applies for $E_{\mathrm{m}, \mathrm{g}, \mathrm{mean}}$. However, the COV for the bending stiffness recommended in [31] seems to be significantly overestimated.

As mentioned above, within both strength classes, three kinds of GLT beams are produced: random, homogeneous and inhomogeneous GLT beams. Between the three types, no unambiguous differences could be detected; neither for $f_{\mathrm{m}, \mathrm{g}}$ nor for $E_{\mathrm{m}, \mathrm{g}}$. This might be the result of (a) the relatively low variability of the material properties within one strength grade or (b) the small sample size.

\subsection{Type of failure}

All investigated GLT beams failed under bending; i.e. the lower lamellas show tensile failures within the area of high bending moment. The tensile failure of the failed lamellas are inspected in more detail. Therefore, a distinction between following three types of failure is made: (a) tensile failure of the lamella within the area of a knot cluster-a knot cluster is defined as a lamella cross-section with tKAR $\geq 0.1$, (b) tensile failure of the lamella within the area of a FJ, and (c) tensile failure within clear wood. In the case that a lamella failed because of a combination of more than one failure type, only the leading failure is 


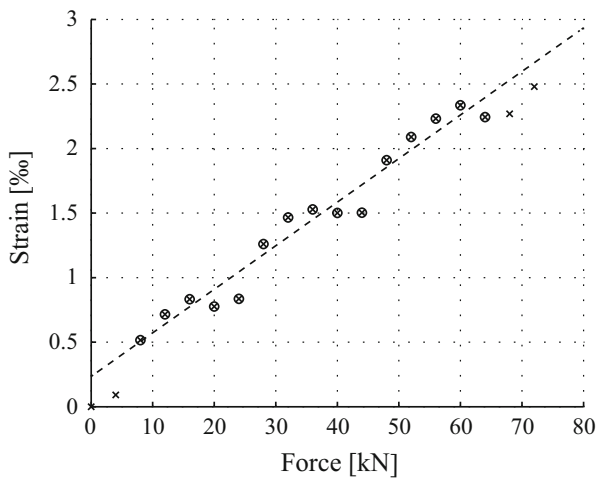

Fig. 6 Force-strain curve

documented. In Table 1 the type of failure of the lowest two lamellas are summarised.

The identified types of failure are different for the specific strength classes. In the lower strength class GL24h: 9 knot clusters, 3 clear wood and no FJ-failure are detected in the lowest lamella. In contrast the upper strength class GL36h show 5 knot clusters, 2 clear wood and $5 \mathrm{FJ}$-failure. The results corresponds to the investigations of former studies and shows that the influence of FJ is getting more important for higher strength classes.

\subsection{Deformation measurement-main stressed area}

On four GLT beams the strains are analysed over the entire main stressed area (area where the bending moment is maximum). For the investigation a regular setup of the light emitting diodes (LED) is chosen; see Fig. 6. The vertical distance between the LEDs corresponds to the thickness of the lamella $t_{1} \approx 40 \mathrm{~mm}$. In horizontal direction a distance between the LEDs of $50 \mathrm{~mm}$ is chosen. Using this LED setup the entire beam height over a length of $3,300 \mathrm{~mm}$ is investigated; i.e. that only the outmost $1,350 \mathrm{~mm}$ (on both sides) are outside the optical range of the measurement device.

For the estimation of the local strains the measured coordinates are discredited to groups of $\Delta F=4 \mathrm{kN}$; i.e. for each load interval $\Delta F$ the mean position of the LEDs is calculated. Based on this, the distances between the LEDs are calculated for each load interval. Afterwords the strains are calculated according to Eq. (6); where $\varepsilon_{i}$ is the calculated strain up to load interval $i, \Delta l_{i}$ is the change of length up to load interval $i, l_{0}$ is the initial length (distance between two adjacent LEDs on the unloaded GLT beam), and $l_{i}$ is the length at the load interval $i$ (distance between two adjacent LEDs at the load interval $i$ ).

$\varepsilon_{i}=\frac{\Delta l_{i}}{l_{0}}=\frac{l_{i}-l_{0}}{l_{0}}$

Figure 7 shows the measured strains between two adjacent LEDs, located somewhere in the middle of beam L25-R-1 (illustrated with a cross). It is obvious that the measurements show some variability; i.e. they are not exactly on a straight line. As a result it is difficult to make a meaningful estimation of the 'real' strains. Within this study the 'real' strains are estimated with the average increase of the strains; i.e. with the gradient of the regression line (slope parameter). Therefore a linear regression analysis according to Eq. (7) is performed; where $\varepsilon$ is the measured strain, $F$ is the load, $\beta_{0}$ is the scale parameter, $\beta_{1}$ is the slope parameter, and $e$ is the error term. To avoid erroneous measurements in the initial phase and in the final phase, the regression analysis is made with the strains between $0.1 F_{\mathrm{u}}$ and $0.9 F_{\mathrm{u}}$. The strains which are used for the regression analysis are illustrated with a circle.

$\varepsilon=\beta_{0}+\beta_{1} F+e$

Based on the regression analysis the strains are calculated with the estimated slope parameter $\beta_{1}$ and the ultimate load $F_{\mathrm{u}}$ according to:

$\epsilon=\beta_{1} F_{\mathrm{u}}$

In addition to the regression parameters also the standard deviation $\sigma_{e}$ of the error term $e$ is calculated Eq. (9); where $e_{i}$ is the error term of an interval $i, n$ is the number of intervals, and $k$ is the number of parameters. $\sigma_{e}$ describes the variation of the measured strains $\varepsilon_{i}$ around the regression line. A large variation of the data set (around the regression line) indicates erroneous measurements. For the calculation the following criteria of acceptance $\sigma_{e} \leq 2 \times 10^{-4}$ is chosen; i.e. areas where $\sigma_{e}>2 \times 10^{-4}$ are identified as erroneous measurements.

$\sigma_{e}^{2}=\sqrt{\frac{\sum_{i=1}^{n} e_{i}^{2}}{n-k}}$

A total amount of 408 markers are glued on each inspected GLT beams. As a result of the large number of LEDs, a relatively small measurement frequency of 


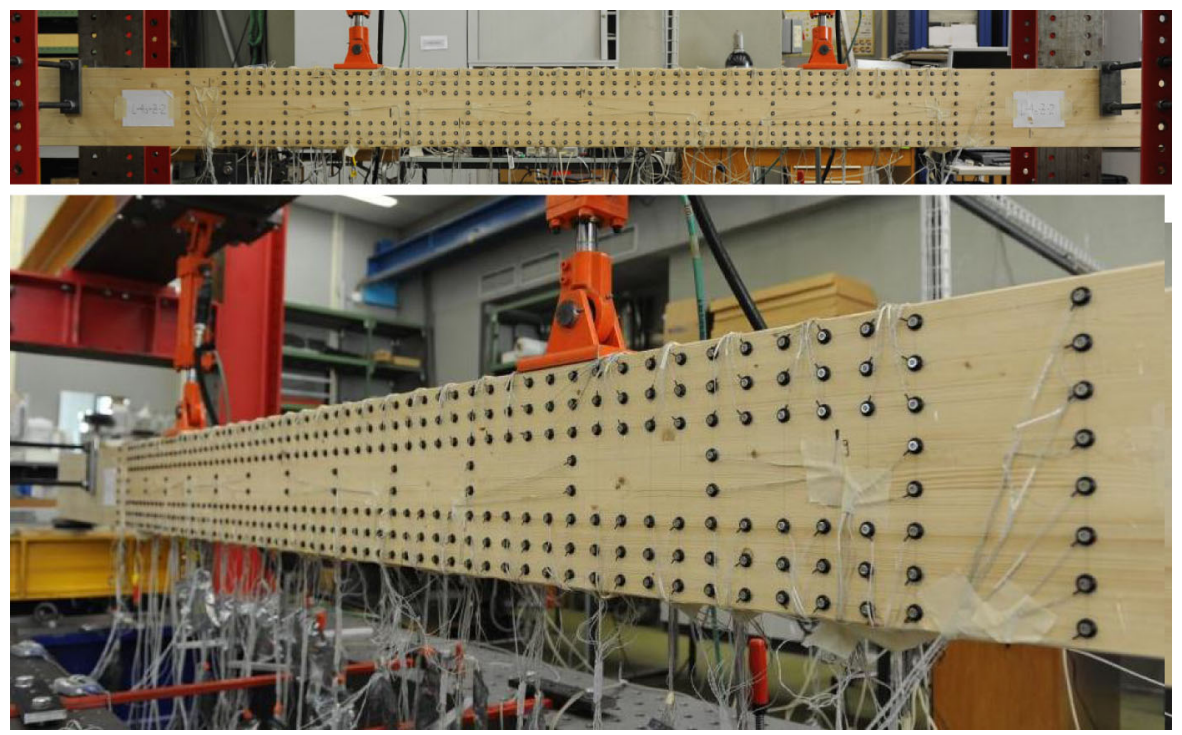

Fig. 7 Illustration of the LED arrangement for the investigation of the entire GLT beam [2]

(a) Stains paralell to the beam axis.

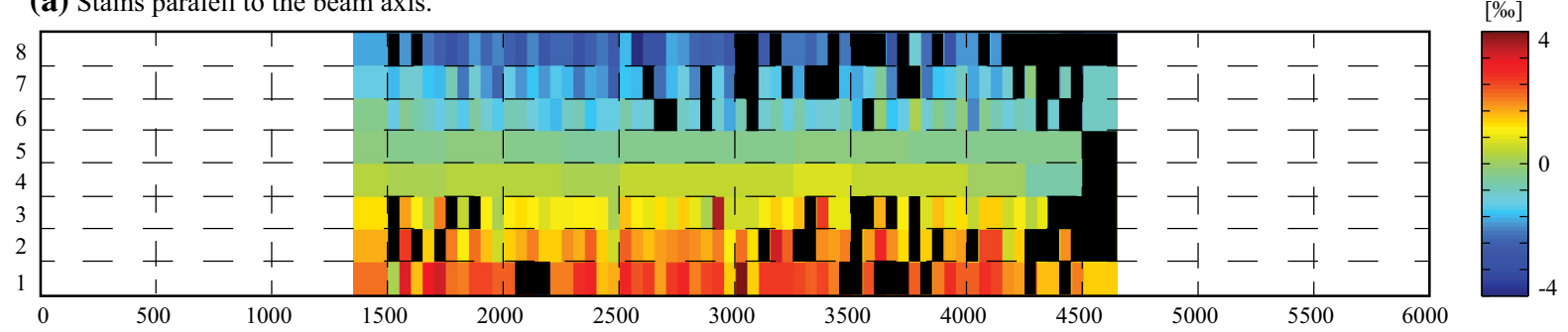

(b) Strain perpenticular to the beam axis

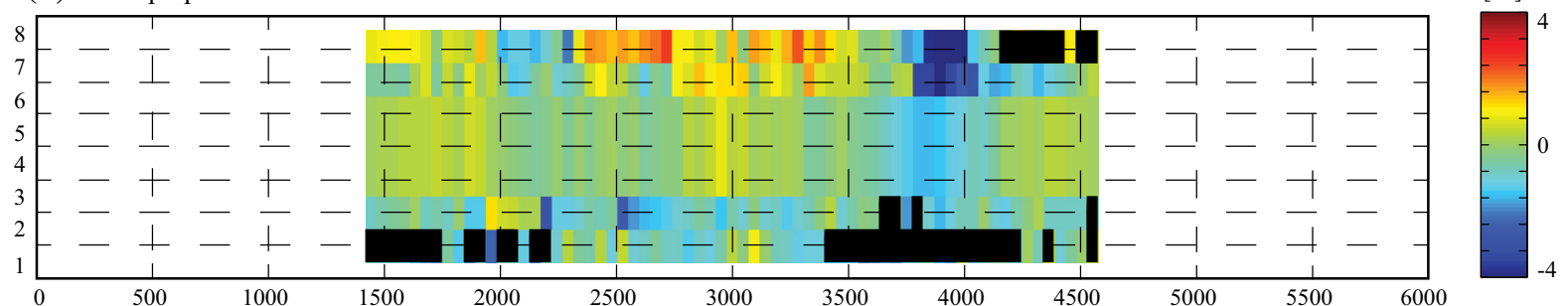

Fig. 8 Estimated strains of L25-R-1: a parallel to the beam axis, $\mathbf{b}$ strain perpendicular to the beam axis

about $2 \mathrm{~Hz}$ is chosen. When attaching the LEDs to the GLT beams, no effort was taken on the beam surface pattern; i.e. the LEDs are glued on the identified position independent of knots, pitch pockets and so on. Unfortunately, LEDs that are glued on knots or other irregularities are often unusable for a local strain estimation. As a result local erroneous measurements occur.
The estimated strains (parallel and perpendicular to the beam axis) are illustrated in Fig. 8. Here the black areas are illustrating erroneous measurements. The estimated strains clearly indicating areas under tension (lower part) and compression (upper part). However, the results are not suitable for an unambiguous description of the local strains. Nevertheless, the inspection shows that the measured strains on the 
(a)

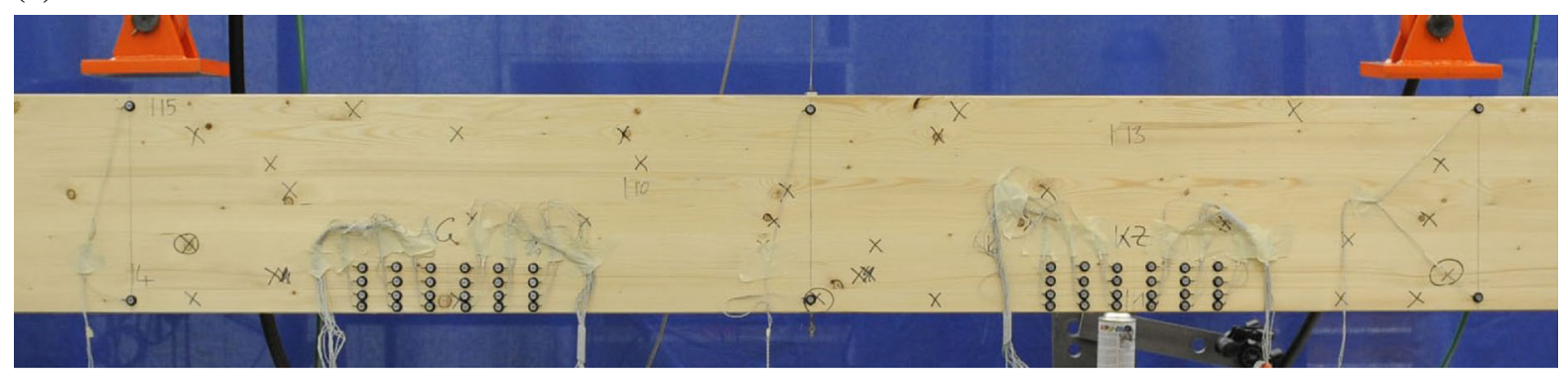

(b)

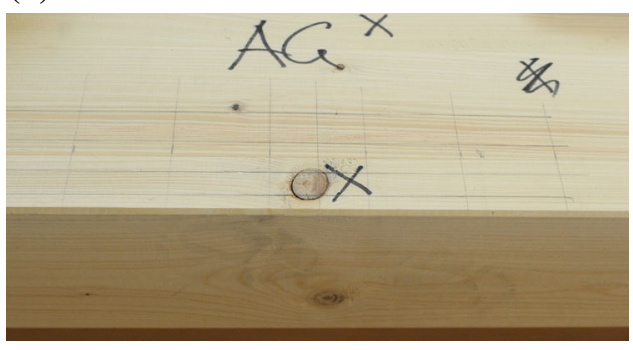

(d)

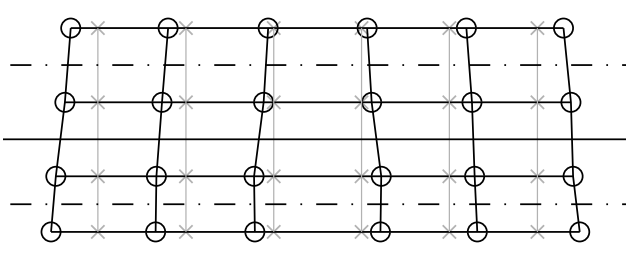

(c)

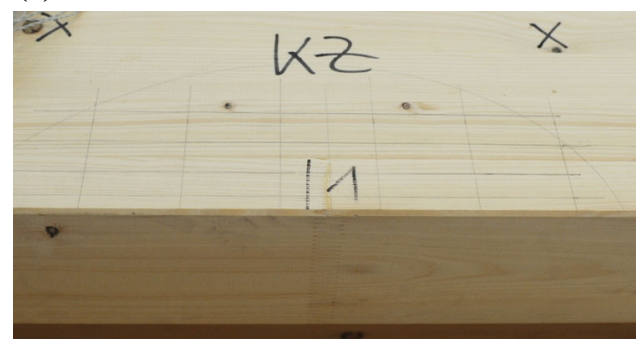

(e)

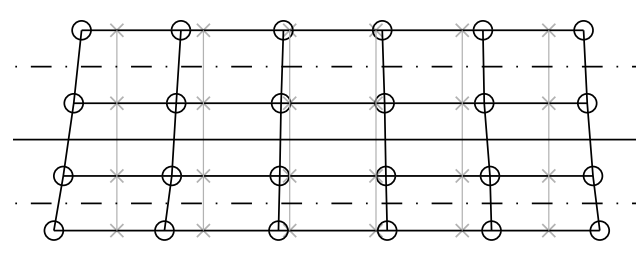

Fig. 9 Example of the LED arrangement within the selected areas of beam L40-IH-4: a entire GLT beam, b area around the knot cluster, $\mathbf{c}$ area around the FJ, and (d,e) estimated strains parallel to the beam axis (100 times oversized)

surface are significantly larger when knots are located near the investigated surface. This indicates a nonlinear strain distribution within the lamella crosssection.

\subsection{Deformation measurement—selected area}

On the other 20 GLT beams, the strains are measured on two selected local areas. Thereby it is focused on the interaction between adjacent lamellas having different material properties; e.g. knot clusters or FJ, that are located in one of the two lowest lamellas. Attention was paid, that the surface around the investigated knots or FJ are free of disturbances, to avoid erroneous measurements, such as described before. Different constellations of knot clusters and FJ are identified and inspected.

Figure 9 illustrates the LED arrangement around a knot cluster and around a FJ located in the lowest lamella, and its associated axial strains (100 times oversized). It is obvious that within the area of the knot cluster, significant larger deformations occur, whereas the strains are only marginal effected by the FJ.

Under consideration of all investigated knot clusters and FJ the following outcomes can be stated: (a) knot clusters are significantly weaker than FJ, (b) FJ are only marginal influencing the strain distribution, and (c) the strain distribution within the lamella cross-section of knot clusters seems to be nonlinear. 


\section{Validation of numerical models using the test results}

One main motivation for the experimental investigations described in this paper is the possibility to validate numerical models, for the estimation of the load-bearing capacity of GLT beams. Due to the large number of parameter, investigated during these study, different models could be validated. Thereunder, wellknown models such as the Model of Foschi and Barrett [22] or the Karlsruher Rechenmodell [1], where the timber specific input variables are the dry density and a knot parameter.

Within the framework of this research project, a numerical strain-based model was developed [17]. The model can be used to estimate the load-bearing capacity, the bending stiffness and the type of failure of GLT beams where (a) the strength and stiffness related indicators measured in the laboratory $\left(E_{\mathrm{dyn}, \mathrm{F}}, \mathrm{tKAR}\right)$, or (b) the machine-grading indicators $\left(E_{\mathrm{m}}, K_{\mathrm{m}}\right)$ are known. For both kind of indicators, the numerical model was validated. In this chapter the principle of this validation is explained for the mentioned model using $E_{\mathrm{dyn}, \mathrm{F}}$ and tKAR.

At first the strength and stiffness properties of timber board sections have to be estimated. Therefore the material model presented in [19] is used. In this model the material properties are estimated using two strength and stiffness related indicators $\left(E_{\mathrm{dyn}, \mathrm{F}}\right.$ and tKAR). To model the material properties of FJ the material model was extended: the strength properties are assumed to be equal to the strength of a knot cluster with $\operatorname{tKAR}=0.20$ and the stiffness properties are assumed to be equal to the mean stiffness of the two adjacent clear wood sections. Both assumptions are investigated in detail and compared with other models presented in the literature; a detailed description is presented in [17].

Under consideration of the strength and stiffness properties of all timber board sections and FJ the load-bearing capacities of the GLT beams are estimated using the above mentioned numerical strain-based model. Within this model the failure of the GLT beams is defined due to an exceed of tensile strength of one timber board section or FJ. Thus, in addition to the load-bearing capacity and the bending stiffness also the type of failure of the GLT beams can be identified.
A comparison between the measured and the estimated values indicate a wide agreement [20]. In average the load-bearing capacity $f_{\mathrm{m}, \mathrm{g}}(\approx 6 \%)$ and the bending stiffness $E_{\mathrm{m}, \mathrm{g}}(\approx 5 \%)$ are slightly underestimated. Furthermore, the type of failure identified with the numerical model is satisfying. In 10 GLT beams (GL24h: 2, GL36h: 8) a FJ failure within the lowest lamella was identified, compared to $5 \mathrm{FJ}$ failure (GL24h: 0, GL36h: 5) observed in the experimental investigation. All 5 'real' FJ failure are detected.

As a result of the wide agreement it seems likely to accurately estimate the material properties of GLT beams, having well-known information about $E_{\mathrm{dyn}, \mathrm{F}}$, tKAR, and FJ. However, as already mentioned, due to the large number of investigated parameters other models can also be validated.

\section{Conclusions \& outlook}

In the present present paper the results of the experimental investigation of GLT beams, having well-known local material properties, are presented. The GLT beams are fabricated out of timber boards of two strength grades - the grading of the timber boards is performed by the GoldenEye-706 grading device. Thus, from all timber boards the machine-grading indicators, i.e. an estimation of the dynamic modulus of elasticity and a knot indicator, are known.

Before the GLT fabrication, the timber boards are investigated non-destructively. That includes a knot assessment, the measurement of different moduli of elasticity and non-destructive tensile tests, where the stiffness properties of knot clusters and clear wood sections are measured.

Out of the investigated timber boards, altogether 24 GLT beams having well-known local material properties are fabricated. Attention was paid that the position of each particular timber board within the GLT beam is precisely-known. To guaranty that the influence of finger joint connections can be investigated, in each GLT beams a finger joint connections is located in the highly stressed area of the lowest lamella.

The GLT beams are investigated during four-point bending tests. From all GLT beams the load-bearing capacity and bending stiffness is measured. Furthermore, the deformation behaviour of local weak 
sections (knot clusters and finger joint connections) within GLT beams under bending, as well as their influence on the bending failure are investigated. Such information is essential to get a better understanding about the load-bearing behaviour of GLT beams.

One advantage of the presented test results is that numerical models for the prediction of the loadbearing capacity of GLT beams can be validated. This is applied on a numerical strain-based model developed by [17]. The predicted load-bearing capacities, bending stiffness and types of failure show a wide agreement to the test results. However, due to the wellknown beam setup the test results can also be used for the validation of existing models.

\section{References}

1. Blaß H, Frese M, Glos P, Denzler J, Linsenmann P, RantaMaunus A (2008) Zuverlässigkeit von Fichten-Brettschichtholz mit modifiziertem Aufbau, vol 11. KIT Scientific Publishing, Karlsruhe. doi:10.5445/KSP/1000008462

2. Caprez A (2012) Experimentelle Untersuchungen zur Ermittlung des Verformungs- und Tragverhaltens von Brettschichtholz. Master-thesis (unpublished), ETH Zurich

3. Colling F (1990) Tragfähigkeit von Biegeträgern aus Brettschichtholz in Abhängigkeit von den festigkeitsrelevanten Einflussgrößen. $\mathrm{PhD}$ thesis, Universität Karlsruhe, Karlsruhe

4. Ehlbeck J, Colling F (1987a) Biegefestigkeit von Brettschichtholz in Abhängigkeit von Rohdichte, Elastizitätsmodul, Ästigkeit und Keilzinkungen der Lamellen, der Lage der Keilzinkungen sowie von der Trägerhöhe. Ingenieurholzbau, Universität Karlsruhe, Forschungsbericht der Versuchsanstalt für Stahl, Holz und Steine, Karlsruhe

5. Ehlbeck J, Colling F (1987b) Die Biegefestigkeit von Brettschichtholzträgern in Abhängigkeit von den Eigenschaften. Bauen mit Holz 89(10):646-655

6. Ehlbeck J, Colling F, Görlacher R (1985a) Einfluß keilgezinkter Lamellen auf die Biegefestigkeit von Brettschichtholzträgern. Eur J Wood Wood Prod 43(8):333-337

7. Ehlbeck J, Colling F, Görlacher R (1985b) Einfluß keilgezinkter Lamellen auf die Biegefestigkeit von Brettschichtholzträgern. Eur J Wood Wood Prod 43(8):367-373

8. Ehlbeck J, Colling F, Görlacher R (1985c) Einfluß keilgezinkter Lamellen auf die Biegefestigkeit von Brettschichtholzträgern. Eur J Wood Wood Prod 43(8):439-442

9. EN 1194 (1999) Timber structures—glued laminated timber-strength classes and determination of characteristic values. German version, European Committee for Standardization, Brussels

10. EN 14080 (2013) Timber structures-glued laminated timber and glued laminated solid timber-requirements. German version, European Committee for Standardization, Brussels
11. EN 14081-4 (2009) Timber structures—strength graded structural timber with rectangular crosssection-Part 4: machine grading - grading machine settings for machine controlled systems. German version, European Committee for Standardization, Brussels

12. EN 338 (2010) Structural timber-strength classes. German version, European Committee for Standardization, Brussels

13. EN 384 (2010) Structural timber-determination of characteristic values of mechanical properties and density. German version, European Committee for Standardization, Brussels

14. EN 408 (2003) Timber structures—structural timber and glued laminated timber-determination of some physical and mechanical properties. German version, European Committee for Standardization, Brussels

15. Falk RH, Colling F (1995) Laminating effects in gluedlaminated timber beams. J Struct Eng 121(12):1857-1863

16. Falk RH, Solli KH, Aasheim E (1992) The performance of glued laminated beams manufactured from machine stress graded Norwegian spruce. Norsk Treteknisk Institutt, Oslo

17. Fink G (2014) Influence of varying material properties on the load-bearing capacity of glued laminated timber. ETH NO. 21746. PhD thesis, ETH Zurich, Zurich

18. Fink G, Kohler J (2012) Zerstörungsfreie Versuche zur Ermittlung des Elastizitätsmodules von Holzbrettern. IBK report no. 339, ETH Zürich, Zurich

19. Fink G, Kohler J (2014) Model for the prediction of the tensile strength and tensile stiffness of knot clusters within structural timber. Eur J Wood Wood Prod 72:331-341

20. Fink G, Frangi A, Kohler J (2013a) Modelling the bending strength of glued laminated timber - considering the natural growth characteristics. In: Proceedings of the 46th meeting, international council for research and innovation in building and construction, working commission W18-timber structures, Vancouver, CIB-W18, paper no. 46-12-1

21. Fink G, Kohler J, Frangi A (2013b) Bending tests on glued laminated timber beams with well-known material properties. IBK report no. 350, ETH Zurich, Zurich

22. Foschi RO, Barrett JD et al (1980) Glued-laminated beam strength: a model. J Struct Div Am Soc Civ Eng 106(ST8): 1735-1754

23. Frese M, Blaß H (2009) Bending strength of spruce glulam. Eur J Wood Wood Prod 67(3):277-286

24. Frese M, Hunger F, Blaß HJ, Glos P (2010) Verifikation von festigkeitsmodellen für die brettschichtholz-biegefestigkeit. Eur J Wood Wood Prod 68(1):99-108

25. Gehri E (1992) Determination of characteristic bending values of glued laminated timber-en-approach and reality. In: Proceedings of the 25th meeting, international council for research and innovation in building and construction, working commission W18 - timber structures, Åhus, CIBW18, paper no. 25-12-1

26. Gehri E (1995) Determination of characteristic bending strength of glued laminated timber. In: Proceedings of the 28th meeting, international council for research and innovation in building and construction, working commission W18-timber structures, Copenhagen, CIB-W18, paper no. 28-12-1

27. Giudiceandrea F (2005) Stress grading lumber by a combination of vibration stress waves and X-ray scanning. In: Proceedings of the 11th international conference on 
scanning technology and process optimization in the wood industry (ScanTech 2005), Las Veagas

28. Görlacher R (1984) Ein neues Messverfahren zur Bestimmung des Elastizittsmoduls von Holz. Holz als Roh- und Werkstoff 42:219-222

29. Heimeshoff B, Glos P (1980) Zugfestigkeit und Biege-EModul von Fichten-Brettlamellen. Eur J Wood Wood Prod 38(2):51-59

30. Isaksson T (1999) Modelling the variability of bending strength in structural timber. PhD thesis, Lund Institute of Technology, Lund

31. JCSS (2006) Probabilistic model code part III-resistance models (3.05 Timber)

32. Johansson C (1990) Strength and stiffness of glulam with laminations of machine stress graded timber. SP RAPPORT 1990:22. Tech. rep., Swedish National Testing and Research Institute, Boras (in Swedish)

33. Önorm DIN, 4074-1 (1996) Sortierung von Holz nach der Tragfhigkeit-Nadelschnittholz. Österreichisches Normungsinstitut, Wien

34. prEN 14080 (2009) Timber structures-glued laminated timber and glued laminated solid timber-requirements. European Committee for Standardization, Brussels
35. Riberholt H, Ehlbeck J, Fewell A (1990) Glued laminated timber - strength classes and determination of characteristic properties. In: Proceedings of the 23th meeting, international council for research and innovation in building and construction, working commission W18-timber structures, Lisbon, CIB-W18, paper no. 23-12-4

36. Schickhofer G (1996) Development of efficient glued laminated timber. In: Proceedings of the 29th meeting, international council for research and innovation in building and construction, working commission W18 - timber structures, Bordeaux, CIB-W18, paper no. 29-12-1

37. Steiger R (1996) Mechanische Eigenschaften von Schweizer Fichten-Bauholz bei Biege-, Zug-, Druck- und kombinierter M/N Beanspruchung. Sortierung von Rund- und Schnittholz mittels Ultraschall René Steiger. PhD thesis, ETH Zurich

38. Thelandersson S, Larsen $\mathrm{H}$ et al (2003) Timber engineering. Wiley West Sussex, London 